\title{
Clinicopathological Studies on the Effect of Insulin as Spray on Diabetic Wound Healing in Albino Rats
}

\author{
Shaimaa Salah, Atef M. Khalil*, Amany S. Mawas, Mouchira Mohamed Mohi Eldin \\ Department of Pathology and Clinical pathology, Faculty of Veterinary Medicine, South Valley University, Egypt
}

DOI: $10.36348 /$ sjpm.2021.v06i01.007 $\quad$ |Received: $26.12 .2020 \mid$ Accepted: $11.01 .2021 \mid$ Published: 22.01 .2021

*Corresponding author: Atef Mohammed Hussein Khalil

Abstract

This study we investigated the effects of insulin spray treatment on skin wounds in diabetic rats. Thirty rats were used for experiment. Rats were divided into 3 groups. group 1 serve as control group. Group 2 was diabetic without treatment. Group 3 was diabetic and treated with insulin spray daily for eight days. Diabetus was inducted by injection of alloxan at dose $100 \mathrm{mg} \backslash \mathrm{kg}$ b.w. Artificial wounds (8-mm diameter) were created in all rats on the day 3 of the experiment. Wound gaps were measured at (Zero, $2^{\text {th }}, 4^{\text {th }}, 6^{\text {th }}$ and $8^{\text {th }}$ ) days post wound (pw). Animals sacrificed at $8^{\text {th }}$ day (p w). Serum was collected for biochemical analyses and wound tissues were excised for histological and immunohistochemical examinations. The results showed significance increase in liver and kidneys analysis, but significance decrease in total antioxidant capacity (TAC) and superoxide dismutase (SOD) in diabetic rats when compared with healthy rats. Level of Malondialdehyde (MDA) and nitric oxide (NO) were increased in group $2 \& 3$ in comparison to control group. Histological findings showed contracted wounds in insulin spray group. Microscopic finding showed septic wounds in diabetic animals in contrast to insulin treated rats, which displayed re-epithelization and remodeling in wound injury at $8^{\text {th }}$ day (ip). It could be concluded that insulin spray is able to accelerate the process of wound healing in diabetic rats.

Keywords: Insulin, Diabetic rats, Wound,Alloxan, Biochemical, Histopathology.

Copyright (C) 2021 The Author(s): This is an open-access article distributed under the terms of the Creative Commons Attribution 4.0 International License (CC BY-NC 4.0) which permits unrestricted use, distribution, and reproduction in any medium for non-commercial use provided the original author and source are credited.

\section{INTRODUCTION}

Diabetes mellitus is one of the major diseases that causes pathological changes and leads to impaired wound healing. Twenty-five percent of diabetic patients will have a diabetic foot ulcer in his or her lifetime [1].Wound healing is a dynamic process involving cellular, molecular, biochemical, and physiological phenomena that result in connective tissue repair and fibrous scar formation and lead to the restoration of the anatomical continuity and functional status of the skin [2]. The wound healing process consists of sequential and overlapping phases, in which dysfunction of any stage could lead to improper wound healing [3]. These phases and their biophysiological functions must occur in the proper sequence, at a specific time and must continue for a specific duration at an optimal intensity [4]. There are many factors that can affect wound healing by interfering with one or more phases in this process, thus causing improper or impaired tissue repair [5]. Disturbance of glucose metabolism, dysregulation of inflammatory response, insufficient of growth factors secretion, and dysfunction of repairing cells and cell signaling are all involved in the morbidity of diabetic impaired wound healing [6]. In diabetic patients, the complication may cause damaged in the skin microvasculature, tissue ischemia ensues, and chronic diabetic wounds develop [7]. Delayed collagen synthesis, impaired epithelialization, and reduced angiogenesis have been observed during the proliferative phase of the healing process in individuals with diabetes mellitus [8]. Another cause for the delaying of wound healing process in diabetic patient is the failure of fibroblasts to produce adequate amounts of extracellular matrix and that keratinocytes do not reepithelialize the wound [9]. Delayed rate of wound closure is associated with the reducedextent of apoptosis in the wound. Angiogenesis increases the delivery of oxygen and other nutrients that are necessary for local collagen synthesis [10].

The insulin accelerates non diabetic wound healing by stimulating the migration of keratinocytes and vascular endothelial cells, thus improving reepithelialization and angiogenesis [13]. Insulin regulating wound inflammation response as well as insulin-induced wound healing [14]. Insulin receptor substrate (IRS) proteins serve as important signaling molecules for insulin. Insulin induced association of IRS-1 and PI-3 kinase, have been found to be involved in insulin regulated growth-promoting effects in 
skin[15]. Disruption of IRS-1, a major cytoplasmic substrate of IR (Insulin receptor), resulted in disrupted and thinner epidermis [16]. Low dose of a topical application of insulin stimulates wound healing in rats with type II diabetes [17]. Topical insulin cream application accelerate diabetic wound healing by shortening the time needed for complete epithelialization in the diabetic without insulin signaling pathways[18]. This work aimed to provides biochemical and histopathological studies on one of treatments (insulin), which use for treat skin wounds in alloxan-induced diabetic rats, in order to reduce the risk of developing a bacterial infection through infection management and remodeling of skin.

\section{MATERIALS AND METHODS \\ Materials}

\section{A- Experimental animals}

Thirty albino male rats (average body weight $175 \pm 200 \mathrm{mg}$ ) at age 3-4 months purchased from laboratory animal house, Cairo, Egypt. The rats were examined for 2 weeks prior the experiment to check its negativity from viral, bacterial and parasitic infections . The study protocol was approved by the animal ethics committee at Cairo University. Animals were housed for 1 week before the experiment for accommodation, inside well-ventilated room and maintained under standard conditions(temperature of $25 \pm{ }^{\circ} \mathrm{C}$, relative humidity of 60-70\%and a 12-hour light/dark cycle),fed a diet of standard commercial pellet and given water and libitum.

\section{A-Chemicals}

\section{1-Alloxan monohydrate}

Alloxan (2, 4, 5, 6-pyrimidinetetrone) is oxygenated pyrimidine derivative of chemical formula $\mathrm{C}_{4} \mathrm{H}_{2} \mathrm{~N}_{2} \mathrm{O}_{2}$.It is present as alloxan monohydrate in aqueous solution. Alloxan is a toxic glucose analogue, which selectively destroys insulin-producing cells (Beta cells) in pancreas when administered to rodents and many other animal species according to[19] Lenzen. Alloxan monohydrate $2 \%$ was obtained from sigma company for pharmaceutical drugs) Sigma Chem. Co., St. Louis, MO, USA; stored at $4^{\circ} \mathrm{C}$.

\section{Preparation of Alloxan}

Alloxan was dissolved in normal saline at room temperature and was vortexed and hided in a dark container to get a pink color, then injected by intravenous (i.v.) routes in overnight fasted rats. The rats were received $100 \mathrm{mg} / \mathrm{kg}$ body weight of alloxan [20].

2-Glucose solution 5\% was given to the animals for 24 hours to prevent hypoglycemia

\section{3-Insulin}

Isophane insulin suspension with trade name (HUMULIN® N). The insulin was obtained as a vial from (Lilly USA, LLC, Indianapolis, IN 46285, USA
Copyright (C) 1997, Initial U.S. Approval: 1982). Each milliliter of (Humulin N) contains 100 units of insulin human, $0.35 \mathrm{mg}$ of protamine sulfate, $16 \mathrm{mg}$ of glycerin, $3.78 \mathrm{mg}$ of dibasic sodium phosphate, $1.6 \mathrm{mg}$ of metacresol, $0.65 \mathrm{mg}$ of phenol, zinc oxide content adjusted to provide $0.025 \mathrm{mg}$ zinc ion, and Water for Injection. The $\mathrm{pH}$ is 7.0 to 7.5. Sodium hydroxide and/or hydrochloric acid may be added during manufacture to adjust the $\mathrm{PH}$.

\section{Methods}

Preparation of diabetic animals

Before the beginning of experiment with 72 hrs, induction of diabetes was done. After overnight fasting, twenty rats were injected intravenously with one dose of $2 \%$ alloxan in a dose $1.8 \mathrm{ml} / \mathrm{rat}$.The animals were kept for 24 hours under control with $5 \%$ glucose given to prevent hypoglycemia. After $72 \mathrm{hr}$ blood glucose level was estimated using 5010 photometer $^{\circledR}$ apparatus and Glucometer apparatus (on call ${ }^{\circledR}$ plus). The blood glucose levels confirm the development of diabetes. The rats with elevated blood glucose levels $(\geq 350 \mathrm{mg} / \mathrm{dl})$ were considered diabetic and were subject to the wounding procedure.

\section{Artificial wound creation}

Artificial wounds were created on the $3^{\text {rd }}$ day after the induction of diabetes all experimental animals. The rats were be anesthetized with diethyl ether.The dorsal region of each rat was shaved and disinfected with $70 \%$ ethyl alcohol. In the mid-region between infra supra scapular line and the base of the tail, a circular area of full skin thickness was removed with $8-\mathrm{mm}$ diameter punch .The wound was uniform in diameter, depth, and location

\section{Experimental design}

Experimental animals were divided into three groups $(\mathrm{n}=10)$.

\section{Group (1)}

The rats were used as non diabetic control, and the wound didn't receive any treatment.

\section{Group (2)}

The rats were injected intravenous with a single dose of $2 \%$ alloxan monohydrate solution in a dose $1.8 \mathrm{ml} \backslash$ rat, and used as a diabetic control and the wound didn't receive any treatment

\section{Group (3)}

The animals were injected intra-venous with a single dose of $2 \%$ alloxan monohydrate solutionin a dose $1.8 \mathrm{ml} \backslash$ rat, The wound was treated with Human isophan insulin suspension (Humulin $\mathrm{N}$ ) as spray twice daily.

The blood glucose level was measured along the experiment in all animals in groups $(1,2 \& 3)$ at $\left(3^{\text {th }}\right.$, $\left.5^{\text {th }}, 7^{\text {th }}, 8^{\text {th }}\right)$ day from the diabetic induction. The wounds of all experimental animals were examined 
daily. The rate of closure of each individual wound from both control and the treated group will measured using digital caliber and photographed at (Zero, $2^{\text {th }}, 4^{\text {th }}$ , $6^{\text {th }}, 8^{\text {th }}$ ) Post- wounding (p.w).

At the end of experiment, all groups were sacrificed after $8^{\text {th }}$ day post-wound ( $\mathrm{pw}$ ) excision under general anesthesia (diethyl ether) by inhalation. The blood samples were collected from the orbital venous plexus of the eyes and left in clean tubes at room temperature to clot. The serum was separated by centrifugation for 15 minutes at $3000 \mathrm{rpm}$ and collected in labeled Eppendorf's tubes and stored at $-20 \mathrm{C}$ until used for biochemical analysis by spectrophotometer (Dacie \& Lewis, 1991). The entire wound with a margin of approximately $5 \mathrm{~mm}$ of surrounding unwound skin was excised and collected from all sacrificed animals in all groups for histopathological and immunohistochemical examinations.

\section{Wound gap measurement}

The rate of closure of each individual wound from both control and the treated groups will be used as an indicator of wound healing. The diameters of wounds were measured after their induction, at (Zero, $\left.2^{\text {th }}, 4^{\text {th }}, 6^{\text {th }}, 8^{\text {th }}\right)$ day using digital caliber.

\section{Biochemical activities}

\section{A- Liver function test}

Determination of Alanine aminotransferase (ALT) and Aspartate aminotransferase (AST)

Serum ALT and AST activities were determined by calorimetrically using spectrophotometer bio-diagnostic kits produced by bio-diagnostic laboratories, Dokki, Giza, Egypt[21].

\section{Determination of Total Protein}

Total Protein was determined by calorimetrical method using spectrophotometer bio-diagnostic kits produced by bio-diagnostic laboratories, Dokki, Giza, Egypt[22].

\section{Determination of Albumin}

Albumin was determined by calorimetrical method using spectrophotometer bio-diagnostic kits produced by bio-diagnostic laboratories, Dokki, Giza, Egypt [23].

\section{Determination of Globulin}

Globulins were determined by subtraction the value of the albumin from the value of the total protein [24].

Globulin Calculation $(\mathrm{g} / \mathrm{dl})=$ Total Protein - Albumin

\section{B-Kidney function tests \\ 1-Determination of serum urea}

Urea was determined by the enzymatic calorimetric method using spectrophotometer biodiagnostic kits produced by bio-diagnostic laboratories, Dokki, Giza, Egypt [25].

\section{2-Determination of serum creatinine}

Calorimetric determination of serum creatinine level was measured using spectrophotometer biodiagnostic kits produced by bio-diagnostic laboratories, Dokki, Giza, Egypt [26].

\section{B-Antioxidant Activities \\ 1-Total antioxidant capacity}

Total antioxidant capacity was determined by calorimetric method using spectrophotometer biodiagnostic kits produced by bio-diagnostic laboratories, Dokki, Giza, Egypt [27].

The determination of the antioxidative capacity is performed by the reaction of antioxidants in the sample with a defined amount of exogenously provide hydrogen peroxide (H2O2) where the antioxidants in the sample eliminate a certain amount of the provided hydrogen peroxide. The residual $\mathrm{H} 2 \mathrm{O} 2$ is determined colorimetrically by an enzymatic reaction which envolves the conversion of 3,5 , dichloro-2hydroxy benzene-sulphonate to a colored product.

\section{2-Superoxide dismutase (SOD)}

Superoxide dismutase was determined by the calorimetric method using spectrophotometer biodiagnostic kits produced by bio-diagnostic laboratories, Dokki, Giza, Egypt[28].

This assay relies on the ability of the enzyme to inhibit the phenazine methosulphate-mediated reduction of nitroblue tetrazolium dye.

\section{3-Malondialdehyde (MDA)}

Malondialdehyde was determined by the calorimetric method using spectrophotometer biodiagnostic kits produced by bio-diagnostic laboratories, Dokki, Giza, Egypt [29]. Thiobarbituric acid (TBA) reacts with Malondialdehyde (MDA) in acidic medium at temperature of $95^{\circ} \mathrm{C}$ for $30 \mathrm{~min}$ to form thiobarbituric acid reactive product the absorbance of the resultant pink product can be measured at $534 \mathrm{~nm}$.

\section{D-Nitric oxide}

Nitric oxide was determined by calorimetric method using spectrophotometer bio-diagnostic kits produced by bio-diagnostic laboratories, Dokki, Giza, Egypt [30].

In acid medium and in the presence of nitrite the formed nitrous acid diazotise sulphanilamide and the product are coupled with $\mathrm{N}$-(1-naphthyl) ethylenediamine. The resulting azo dye has a bright reddish-purple color which can be measured at $540 \mathrm{~nm}$.

\section{3-Histopathological Examination}

All of the skin samples were fixed in $10 \%$ neutral buffered formalin solution ( $\mathrm{pH}$ 7.4) and passed in alcohols then embedded in paraffin. Paraffin samples were cut $(5 \mathrm{~mm})$ and stained with hematoxylin and eosin 
(H\&E) and Masson's trichrome histopathological examination [31].

4-Immunohistochemistry examination used for detects transformed growth factor-B-1 (TGF- $\gamma-1)$ and Vascular Endothelial growth factor (VEGF) protein expression

Two slides obtained from the best representative formalin-fixed paraffin-embedded blocks of wound healing specimen for immunohistochemistry staining. The sections were deparaffinized in xylene and rehydrated in descending grades of ethyl alcohols. The slides were immersed in a covered plastic container with Target Retrieval Solution (0.05 M citrate buffer, $\mathrm{pH}$ 6.8) and placed in an autoclave at $121^{\circ} \mathrm{C}$ for 10 minutes. Endogenous peroxidase activity was quenched with peroxidase blocking solution for 10 minutes at room temperature. After thoroughly washing in phosphate-buffered saline (PBS), the protein block serum free was applied to block nonspecific binding for 10 minutes at room temperature. Slides were incubated with the specific primary antibody for VEGF (Polyclonal rabbit, dilution1/200, PA5-16754, Invitrogen, USA) and for TGF- $\beta-1$ (Polyclonal rabbit, dilution1/100, PA1-9574, Invitrogen, USA) in a moist chamber at $4^{\circ} \mathrm{C}$ overnight. After washing in PBS for 10 minutes, the sections were incubated with goat antirabbit secondary antibody (cat. no. K4003, EnVision+TM System Horseradish Peroxidase Labelled Polymer; Dako) for 30 minutes (at room temperature). Slides were visualized with DAB kit (3, 3'-Diaminobenzidine). All slides were counter stained with hematoxylin, rinsed in distilled water again, dehydrated and mounted. The sections were examined qualitatively under a bright field microscope at 100 to $40 \mathrm{x}$ magnification for changes in the expression of TGF-B-1 and VEGF in wound tissue among the groups. For quantitative analysis of expression labeling indexes were determined as the ratio of positively stained cells to the total number of cells per visual field. For this study, only cell-associated staining was considered. The criteria for a positively expressing cell were the existence of a clear cell structure with nucleolus and clear specific staining of the cytoplasm. The overall number of evaluated cells per section was $900 \pm 100$ cells (at least 3fields per section were examined with $400 \mathrm{x}$ magnification) According to [32].

\section{Statistics}

Statistics Analysis was done using one-way analysis of variance (ANOVA). It was done to compare between control and other treated groups, followed by post-hoc analysis (Dunnett's test)using SPSS(statistical package for social sciences)version 17 according to [33]. The data were presented in form of Mean \pm standard Deviation. The differences was considered statically significant when $\mathrm{p}<(0.05)$.

\section{RESULTS}

\section{A- Biochemical analysis \\ 1- Blood glucose level}

Table (1) Fig.(1) was shown different assessment of blood glucose level in the rats in all groups (1-3) during the experiment, and highly significance blood glucose levels in group $(2,3)$ were detected compared to control till the $8^{\text {th }}$ day. Moreover, significant decrease in blood glucose level was observed in of the group (3) when compared to diabetic control group 2 .

\section{2-Liver function results}

a-Alanine aminotransferase (ALT) and Aspartate aminotransferase (AST)

Table (2), Figs. (2, 3) was shown no significant changes in the mean level of AST of the diabetic group $(2,3)$ when compared with the control group (1) but the mean level of ALT in diabetic group $(2,3)$ showed significant increase when compared with of the group (1). Both (AST and ALT) enzymes in the insulin treated group (3) not induced any significances compared to diabetic group (2).

\section{b -Total protein, Albumin, and globulin}

Table (3), Figs $(4,5,6)$ showed that there was significant decrease in the levels of the total protein, globulin in the diabetic and insulin groups $(2,3)$ when compared to control group (1). Meanwhile, the levels of the albumin displayed no significant change in the groups $(2,3)$ when compared to control group (1). Otherwise, No significant change showed in the levels of the total protein, albumin, and globulin in the insulin treated group (3) when compared to the diabetic group (2).

\section{3-Kidney function tests \\ a- Urea and creatinine}

Table (4), Figs $(7,8)$ there is a significant increase in the level of urea and creatinine of the group $(2-3)$ when compared with the group (1). While, there was non-significant increase in the urea and creatinine of the group (3) when compared to the group (2).

\section{4- Antioxidants examinations a- Total antioxidant capacity (TAC)}

Table (5), Figs (9) showed that there was a significant decrease in the level of Total antioxidant capacity of group $(2,3)$ in comparison with group (1). Moreover, no significant change was shown in the groups (3) in the total antioxidant capacity when compared to group (2).

\section{b- Superoxide dismutase (SOD)}

Table (5), Figs (10) was shown significant decrease in the level of superoxide dismutase in groups (2 - 3) in comparison to group (1). There was a significant increase in the level of superoxide dismutase of group (3) in comparison with group (2). 


\section{c- Malondialdehyde (MDA)}

Table (5), Figs (11) was shown significant increase in the level of Malondialdehyde in group (2) when compared to group (1). There was a significant decrease in the Malondialdehyde of groups (3) in comparison with group (2). Otherwise there was no significant change in the Malondialdehyde of the groups (3) when compared to group (1).

\section{d- Nitric oxide}

Table (6), Figs (12) showed that there was a significant increase in the level of nitric oxide of groups (2 - 3) in comparison group (1). Moreover the groups (3) showed no significant change in the nitric oxide when compared to group (2).

\section{B-Histopathological findings Wound Closure}

Table (7) (Fig.13) showed the wound contraction was higher in insulin group giving them rapid healing ratio in comparison to non-diabetic and diabetic control groups. Improved healing and small wound size was noticed at $4^{\text {th }}$ of treatment relative to the wounds in the diabetic control and diabetic nontreated group.

\section{Clinical Signs}

Clean scar wounds with bright red healthy granulation tissue were observed in insulin treated group (3) in the majority rats. The wounds of the diabetic control rats (2) were unclean, scar with pus formation in all rats were observed, in contrast with control group (1) which noticed complete closure in skin wound (Figure 14).

\section{Microscopical examination}

Histological sections of the wound tissue on $8^{\text {th }}$ day post-wounding in diabetic rats in control nondiabetic non-treated wound (1) showed re-epithelized in the epidermal cells. The diabetic non-treated group, showed large area of unhealthy granulation tissue with hemorrhages and inflammatory reaction. Meanwhle, the topical application of insulin spray, the wound appeared smaller with early epithelization and by regulation of wound inflammatory reaction resulting in complete epidermal restoration accompanied with abundance granulation tissue formation. Dermal collagen fiber deposition appeared in all groups and thick epidermal layer in Insulin treated wounds with Masson's trichrome stain (Figure 15 a-e).

\section{Immunohistochemistry}

Wound inflammatory response was analyzed by examination of TGF-B-1 and VEGF expression levels on wound area. Wound treated with topical application of Insulin spray showed more positivity of TGF-B-1 and VEGF in day 8 after wounding, suggestion earlier initiation of inflammatory response comparing to the control non-diabetic untreated and control diabetic non-treated groups (Figure 16).

Table-1: The mean \pm standard deviation of blood glucose level of the albino rats of the non-diabetic (gp 1), and diabetic control group (gp 2), diabetic- insulin treated group at $\left(3^{\text {th }}, 5^{\text {th }}, 7^{\text {th }}, 8^{\text {th }}\right)$ day p.w

\begin{tabular}{|l|l|l|l|l|}
\hline \multicolumn{4}{|l|}{ Blood glucose level $(\mathbf{m g} / \mathbf{d l})$} \\
\hline Groups & $\mathbf{3}^{\text {th }}$ day & $\mathbf{5}^{\text {th }}$ day & $\mathbf{7}^{\text {th }}$ day & $\mathbf{8}^{\text {th }}$ day \\
\hline Group 1 & $97.6 \pm 11.4$ & $95.0 \pm 11.7$ & $111.2 \pm 8.1$ & $102.6 \pm 8.9$ \\
\hline Group 2 & $417.4 \pm 8.3^{\mathrm{a}}$ & $468.4 \pm 7.5^{\mathrm{a}}$ & $396.8 \pm 8.7^{\mathrm{a}}$ & $406.4 \pm 11.5^{\mathrm{a}}$ \\
\hline Group 3 & $443.4 \pm 8.1^{\mathrm{ab}}$ & $367.4 \pm 11.8^{\mathrm{a}}$ & $595.4 \pm 10.1^{\mathrm{ab}}$ & $474.4 \pm 9.6^{\text {ab }}$ \\
\hline
\end{tabular}

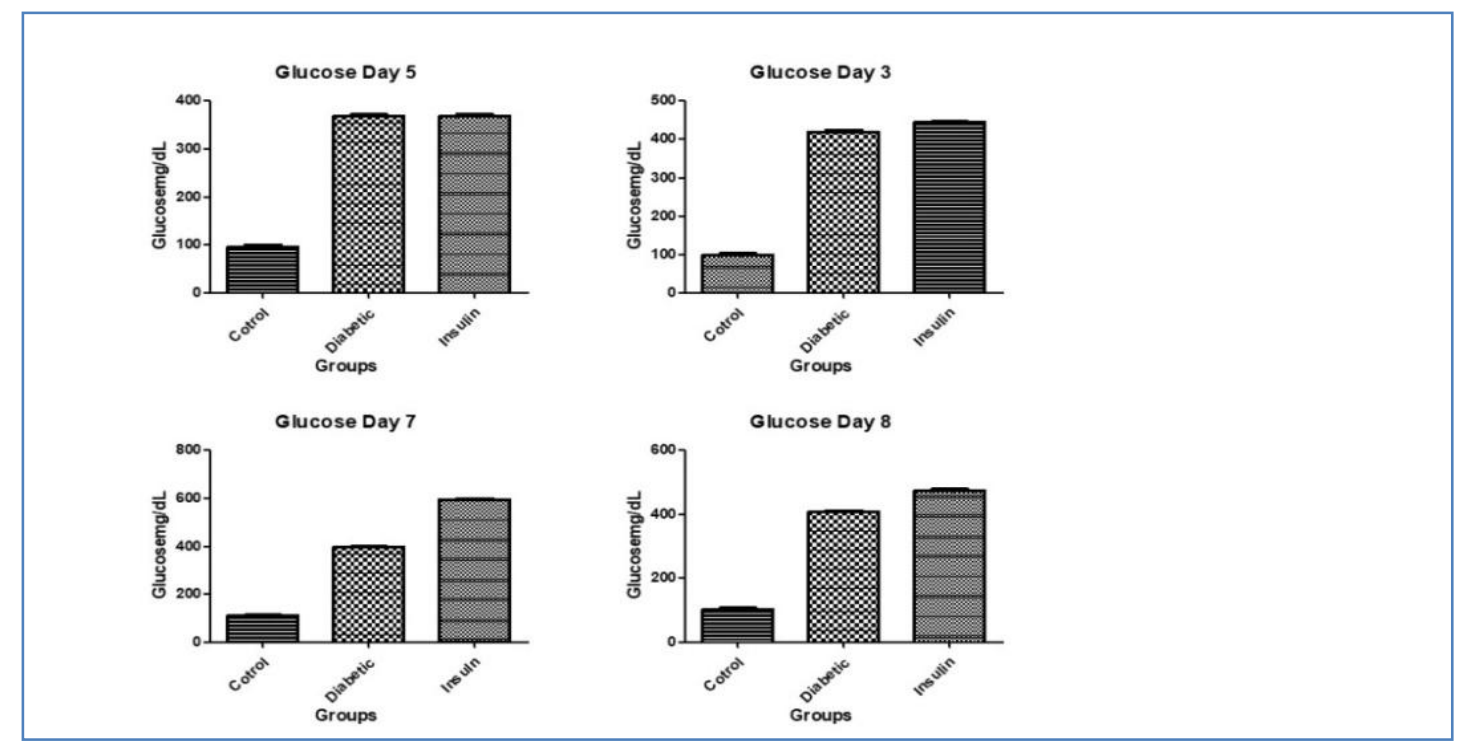

Fig-1: Mean of the Glucose (mg/dL) of the rats of group (1) (Non diabetic control), group (2) (diabetic control), group (3) (diabetic treated with insulin), at the 3rd 5th, 7th, and 8th day 
Table-2: The mean \pm standard deviation of the liver function tests of control group (1), diabetic group (2) and insulin treated group (3)

\begin{tabular}{|l|l|l|}
\hline \multicolumn{4}{|l|}{ Liver function tests } \\
\hline Groups & AST(UI/I) & ALT(UI/I) \\
\hline Group 1 & $35.7 \pm 2.9$ & $29.9 \pm 2.8$ \\
\hline Group 2 & $40 \pm 2.1$ & $39.5 \pm 1.7^{\mathrm{a}}$ \\
\hline Group 3 & $36.4 \pm 2.7$ & $35.6 \pm 2.2^{\mathrm{a}}$ \\
\hline
\end{tabular}

a : referring to significant changes in comparison with control group(1)when $\mathrm{p}<0.05 \%$.

b : referring to significant changes in comparison with diabetic group(2)when $\mathrm{p}<0.05 \%$.

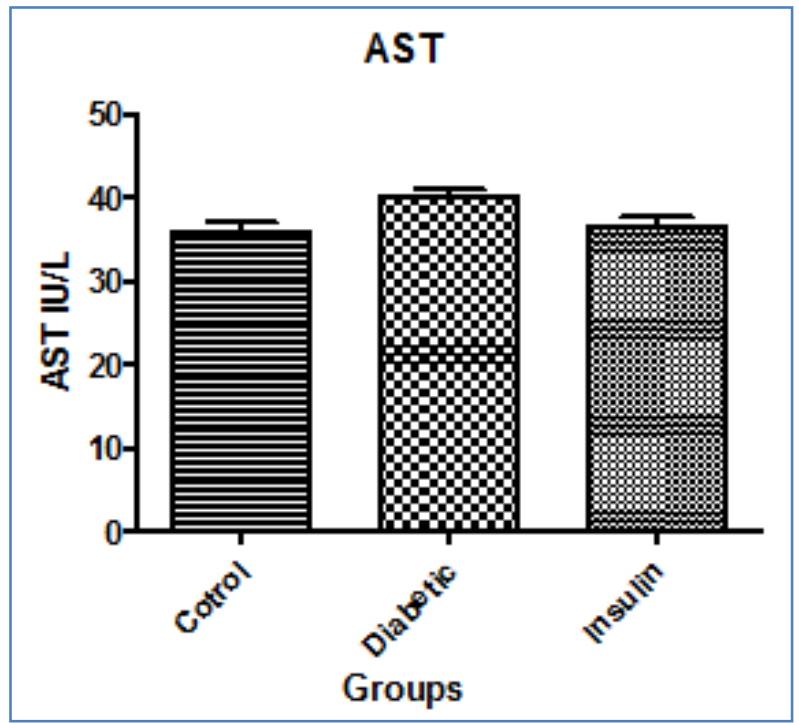

Fig-2: Mean of the AST (IU/L) of the rats of group

(1) (Non diabetic control), group (2) (diabetic control), and group (3) at the $8^{\text {th }}$ day

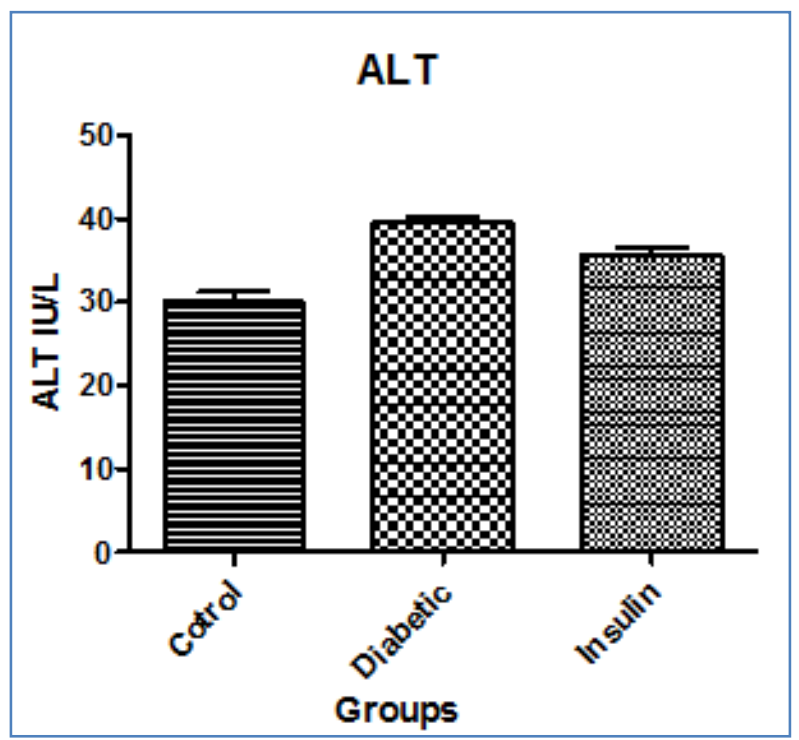

Fig-3: Mean of the AST (IU/L) of the rats of group

(1) (Non diabetic control), group (2) (diabetic control), and group (3) at the $8^{\text {th }}$ day
Table-3: Mean \pm standard deviation of the Total protein, albumin, and globulin of control group (1), diabetic group (2) and insulin treated group (3)

Protein parameter

\begin{tabular}{|l|l|l|l|}
\hline Groups & $\begin{array}{l}\text { Total protein } \\
(\mathbf{m g} / \mathbf{d l})\end{array}$ & $\begin{array}{l}\text { Albumin } \\
(\mathbf{m g} / \mathbf{d l})\end{array}$ & $\begin{array}{l}\text { Globulin } \\
(\mathbf{m g} / \mathbf{d l})\end{array}$ \\
\hline Group 1 & $6.3 \pm 0.50$ & $2.8 \pm 0.15$ & $3.4 \pm 0.29$ \\
\hline Group 2 & $4.26 \pm 0.4^{\mathrm{a}}$ & $2.12 \pm 0.46$ & $2.4 \pm 0.17^{\mathrm{a}}$ \\
\hline Group 3 & $4.7 \pm 0.7^{\mathrm{a}}$ & $2.7 \pm 0.56$ & $2.0 \pm 0.38^{\mathrm{a}}$ \\
\hline
\end{tabular}

a : referring to significant changes in comparison with control group(1)when $\mathrm{p}<0.05 \%$.

b : referring to significant changes in comparison with diabetic group(2)when $\mathrm{p}<0.05 \%$.

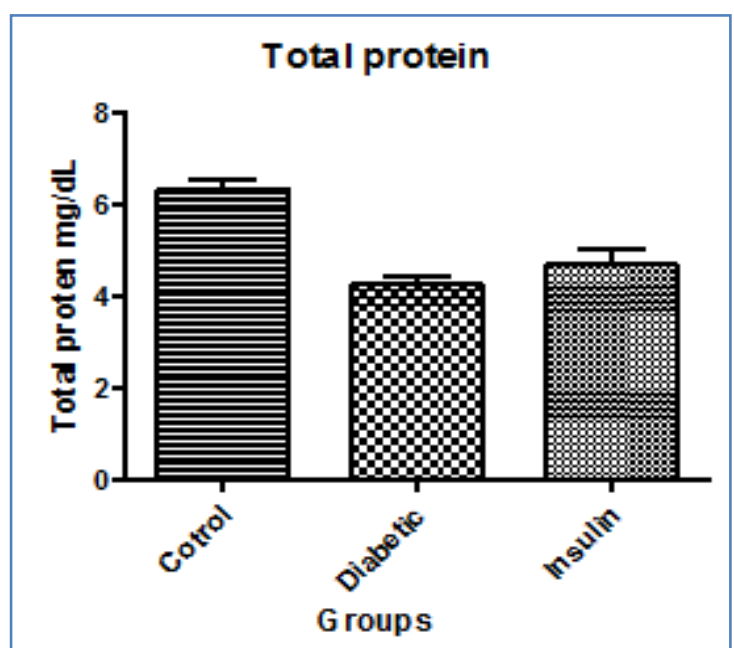

Fig-4: Mean of Total protein (mg/dl) of the rats of group (1) (Non diabetic control), group (2) (diabetic control), group (3) (diabetic treated with insulin), at the $8^{\text {th }}$ day

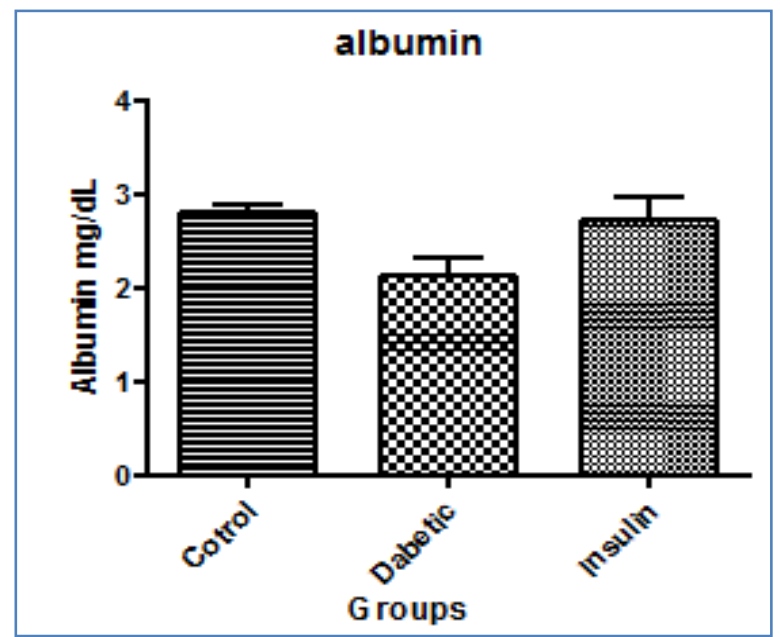

Fig-5: Mean of Albumin (mg/dl) of the rats of group (1) (Non diabetic control), group (2) (diabetic control), group (3) (diabetic treated with insulin), group (4) (diabetic treated with sesame), and group (5) (diabetic treated with chlorine dioxide) at the $8^{\text {th }}$ day 


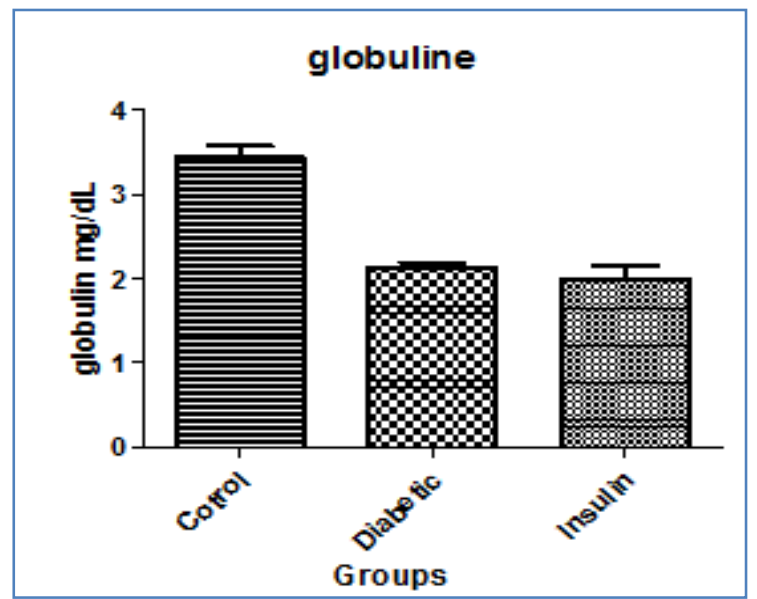

Fig-6: Mean of Globulin (mg/dl) of the rats of group 1(Non diabetic control), group 2 (diabetic control), group 3 (diabetic treated with insulin at the day 8

Table-4: Mean \pm Standard Deviation of the urea and creatinine of control group (1), diabetic group (2) and insulin treated group (3)

\begin{tabular}{|l|l|l|}
\hline \multicolumn{3}{|c|}{ Kidney function analysis } \\
\hline Groups & Urea (mg/dl) & Creatinine (mg/dl) \\
\hline Group 1 & $25 \pm 4.3$ & $10 \pm 0.1$ \\
\hline Group 2 & $47.1 \pm 2.3^{\mathrm{a}}$ & $1.7 \pm 0.2^{\mathrm{a}}$ \\
\hline Group 3 & $45.9 \pm 2^{\mathrm{a}}$ & $1.5 \pm 0.2^{\mathrm{a}}$ \\
\hline
\end{tabular}

a: referring to significant changes in comparison with control group(1)when $\mathrm{p}<0.05 \%$.

b: referring to significant changes in comparison with diabetic group $(2)$ when $\mathrm{p}<0.05 \%$.

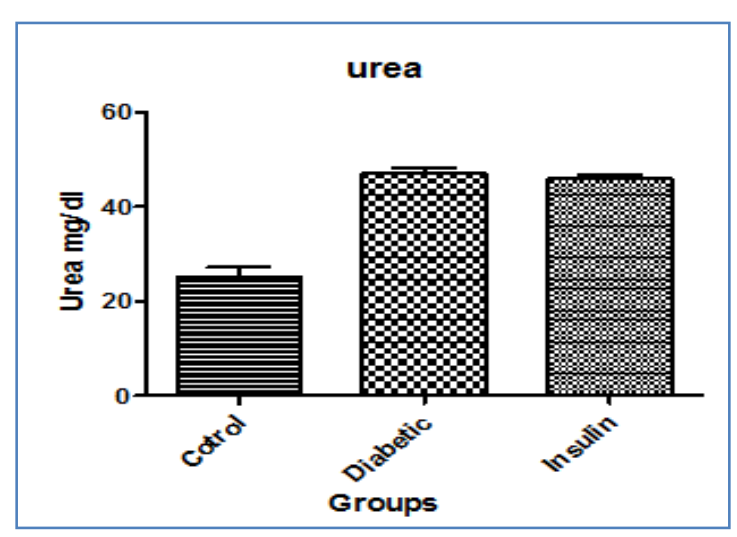

Fig-7: Mean of urea (mg/dl) of the rats of group (1) (Non diabetic control), group (2) (diabetic control), and group (3) (diabetic treated with insulin) at the $8^{\text {th }}$ day

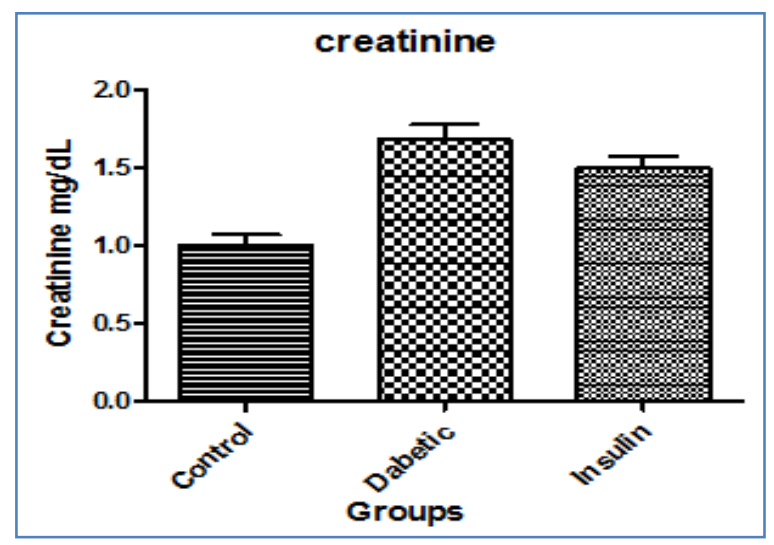

Fig-8: Mean of Creatinine (mg/dl) of the rats of group (1) (Non diabetic control), group (2) (diabetic control), and group (3) (diabetic treated with insulin) at the $8^{\text {th }}$ day

Table-5: Mean \pm Standard Deviation of Total antioxidant capacity of control group (1), diabetic group (2) and insulin treated group (3).

\begin{tabular}{|l|l|l|l|}
\hline & $\begin{array}{l}\text { Total antioxidant } \\
\text { capacity }\end{array}$ & $\begin{array}{l}\text { Superoxide } \\
\text { dismutase(SOD) }\end{array}$ & $\begin{array}{l}\text { Malondialdehyde } \\
\text { (MDA) }\end{array}$ \\
\hline Group 1 & $2.24 \pm 0.2$ & $155.4 \pm 23$ & $8.5 \pm 1.3$ \\
\hline Group 2 & $1.01 \pm 0.35^{\mathrm{a}}$ & $82.8 \pm 5.2^{\mathrm{a}}$ & $18.3 \pm 1.1^{\mathrm{a}}$ \\
\hline Group 3 & $1.3 \pm 0.26^{\mathrm{a}}$ & $114 \pm 5.3^{\mathrm{ab}}$ & $10.8 \pm 1.1^{\mathrm{b}}$ \\
\hline
\end{tabular}

a: referring to significant changes in comparison with control group (1)when $\mathrm{p}<0.05 \%$.

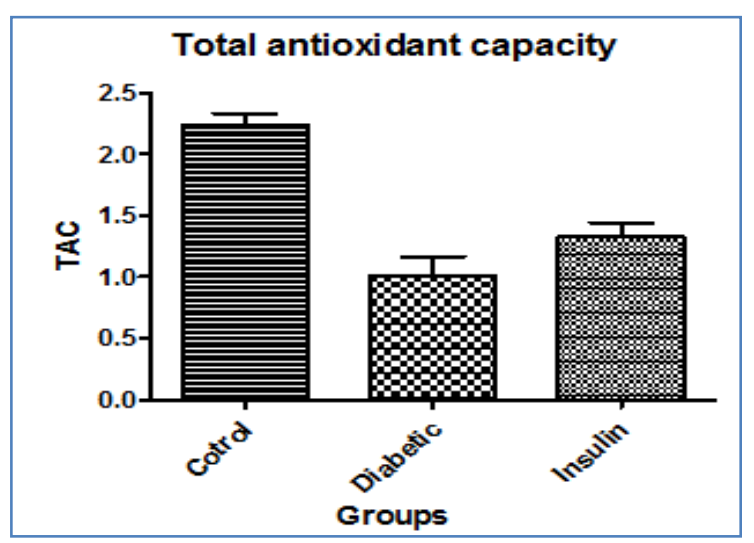

Fig-9: Mean of Total antioxidant capacity (IU/L) of the rats of group (1) (Non diabetic control), group (2) (diabetic control), and group (3) (diabetic treated with insulin) at the $8^{\text {th }}$ day b: referring to significant changes in comparison with diabetic group (2)when $\mathrm{p}<0.05 \%$.

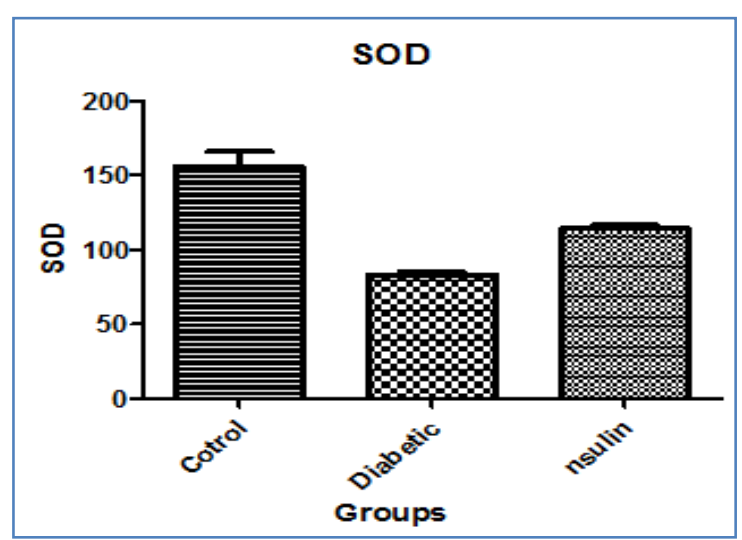

Fig-10: Mean of Superoxide dismutase (IU/L) of the rats of group (1) (Non diabetic control), group (2) (diabetic control), and group (3) (diabetic treated with insulin) at the $8^{\text {th }}$ day 


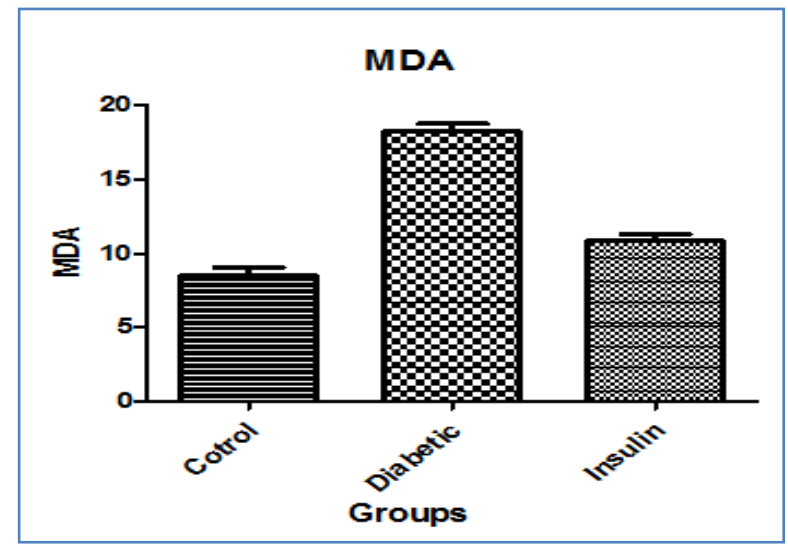

Fig-11: Mean of Malondialdehyde (IU/L) of the rats of group (1) (Non diabetic control), group (2) (diabetic control), and group (3) (diabetic treated with insulin) at the $8^{\text {th }}$ day

Table-6: Mean \pm Standard Deviation of Nitric oxide of control group (1), diabetic group (2) and insulin treated

\begin{tabular}{|l|l|}
\hline & group (3 \\
\hline Group 1 & $42.14 \pm 1.3$ \\
\hline Group 2 & $64.2 \pm 2.4 \mathrm{a}$ \\
\hline Group 3 & $60.8 \pm 1.1 \mathrm{a}$ \\
\hline
\end{tabular}

a : referring to significant changes in comparison with control group(1)when $\mathrm{p}<0.05 \%$.

b : referring to significant changes in comparison with diabetic group(2)when $\mathrm{p}<0.05 \%$.

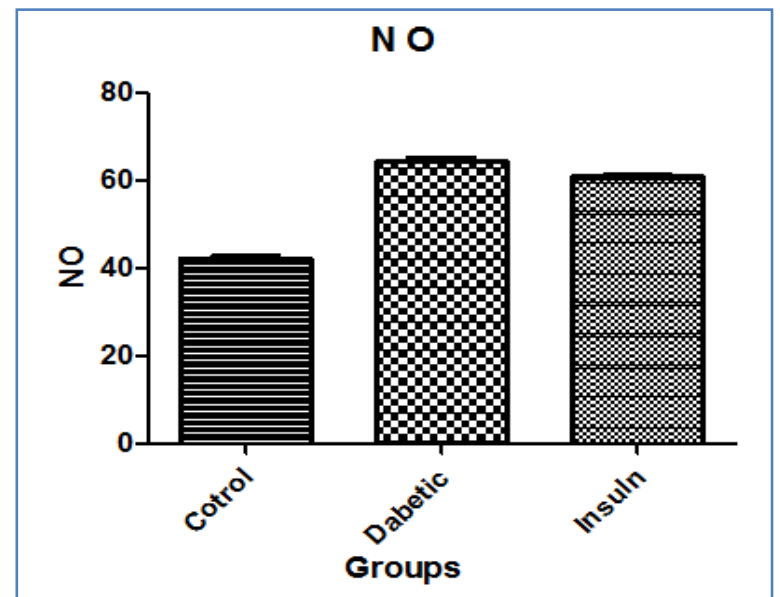

Fig-12: Mean of Nitric oxide (IU/L) of the rats of group (1) (Non diabetic control), group (2) (diabetic control), and group (3) (diabetic treated with insulin) at the $8^{\text {th }}$ day.

Table-7: Values Mean \pm standard deviation of diameter of the wound gap of the non-diabetic (gp 1), and diabetic control group (gp 2), diabetic- insulin treated group at (Zero, $\left.2^{\text {th }}, 4^{\text {th }}, 6^{\text {th }}, 8^{\text {th }}\right)$ day P.w

\begin{tabular}{|l|l|l|l|l|l|}
\hline Diameter of wound gap $(\mathbf{m m})$ & \multicolumn{5}{l|}{ ) } \\
\hline Groups & Zero day & $\mathbf{2}^{\text {nd }}$ day & $\mathbf{4}^{\text {th }}$ day & $\mathbf{6}^{\text {th }}$ day & $\mathbf{8}^{\text {th }}$ day \\
\hline Group 1 & $8 \mathrm{~mm}$ & $6.59 \pm 0.68$ & $6.13 \pm 0.99$ & $5.26 \pm 1.05$ & $4.56 \pm 0.74$ \\
\hline Group 2 & $8 \mathrm{~mm}$ & $7.06 \pm 0.20$ & $6.51 \pm 0.17$ & $5.10 \pm 1.18$ & $4.99 \pm 1.15$ \\
\hline Group 3 & $8 \mathrm{~mm}$ & $4.82 \pm 0.45$ & $4.22 \pm 0.82$ & $3.59 \pm 0.82$ & $2.61 \pm 0.99$ \\
\hline
\end{tabular}

a : referring to significant changes in comparison with control group(1)when $\mathrm{p}<0.05 \%$.

b : referring to significant changes in comparison with diabetic group(2)when $\mathrm{p}<0.05 \%$.

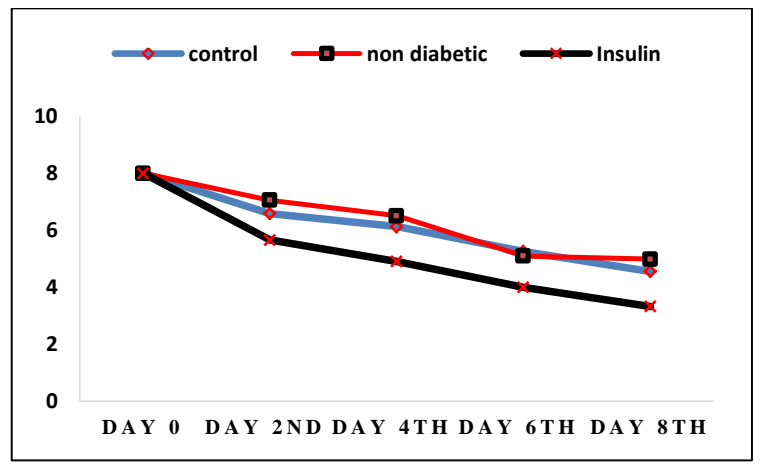

Fig-13: Mean \pm SEM of diameter of wound gap during healing process of the non-diabetic, and diabetic control group, diabetic- insulin treated group at (Zero, $\left.2^{\text {th }}, 4^{\text {th }}, 6^{\text {th }}, 8^{\text {th }}\right)$ day post-wounding

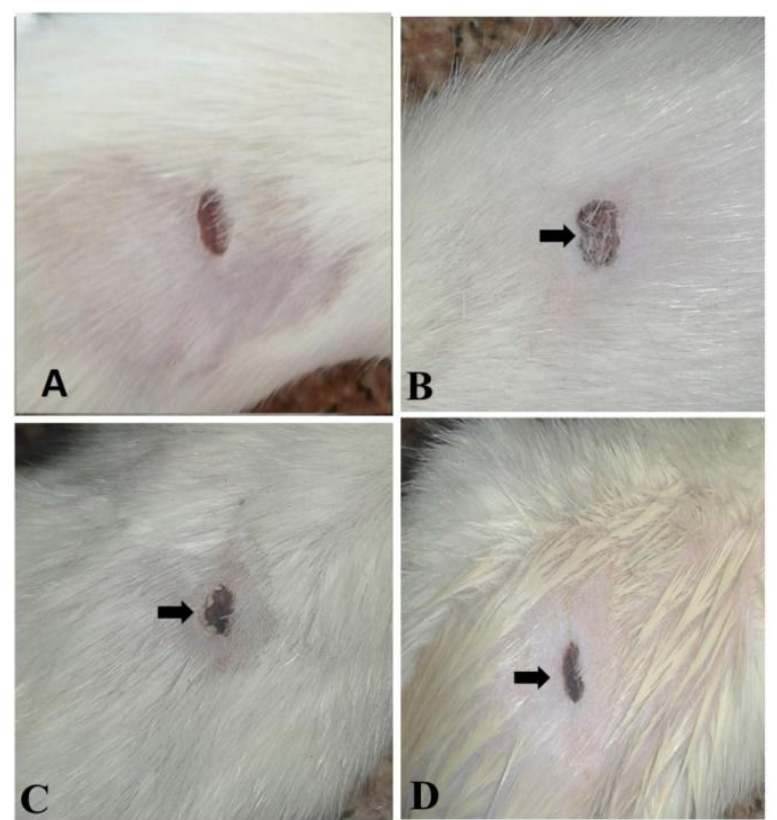

Fig-14: Wound size on $8^{\text {th }}$ day after surgery in diabetic rats (arrows). (A) Non-diabetic non-treated control group (B) Diabetic non-treated control group (C\& D) Insulin group 


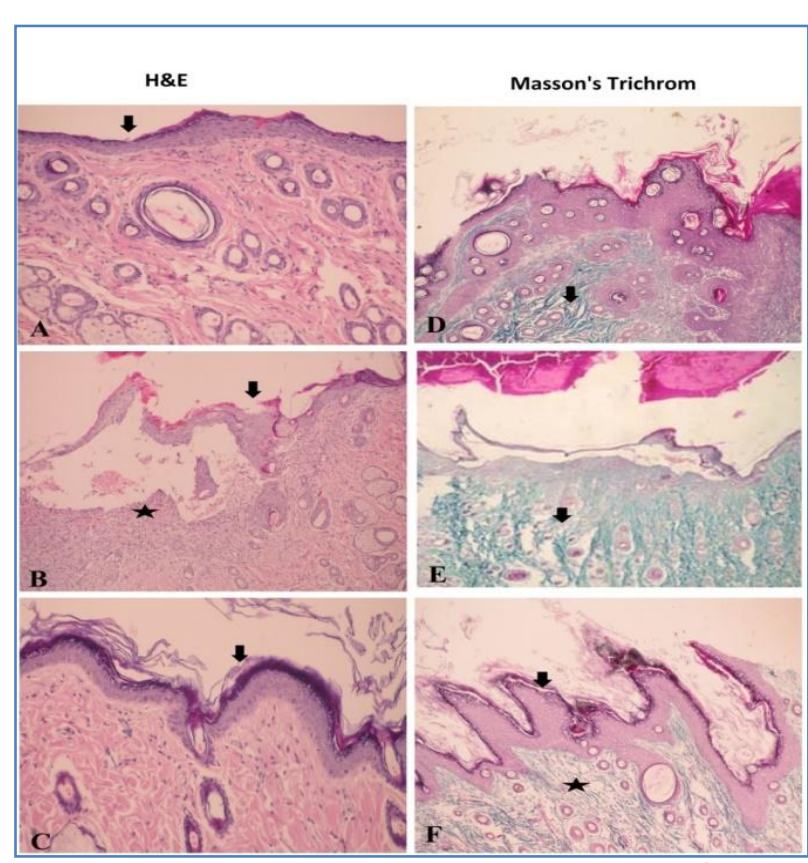

Fig-15: Histological sections of wound tissues on $8^{\text {th }}$ day post-wounding. (A) control non- diabetic wound showing apparently normal epidermal layer (arrow), (B) control diabetic non-treated wound showing detached of epidermal layer (arrow) with an area of hemorrhages accompanied with inflammatory reaction (asterisk),

(C)Topical application of insulin spray showing reepithelization in the epidermal layer with fine scar formation (arrow), (H\&E stain, $10^{\mathrm{X}}$ ). (D, E, F) control group, diabetic group and insuln treated group showing collagen fiber appeared green color with (arrow) (Masson's trichrome stain)

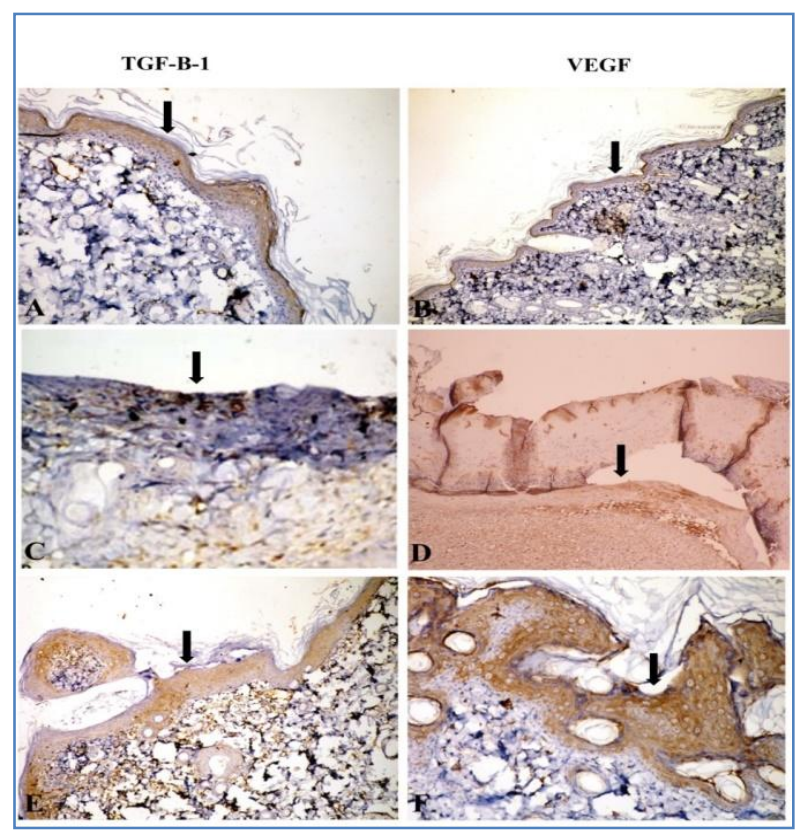

Fig-16: Immunohistochemical staining showing increased expression of TGF-B-1 and VEGF proteins in the epidermal layers (arrows) in case of topical application of insulin spray in comparison with control un-diabetic untreated and control diabetic untreated groups, (A\&B control un-diabetic untreated group, $C \& D$ control diabetic untreated group, E\&F Insulin group), (A, C, E: TGF-B-1 \& B, D, F: VEGF).

\section{DISCUSSION}

The wounds considers cellular and anatomical disruption in body tissues, lead to major problem of public health. It varies from open wounds like incisions and laceration to closed wounds like contusions [34]. Chronic injury usually related to different diseases like diabetes mellitus followed by a microbial infection which delaying of the healing process [35]. Type II diabetes causing a lots of pathological changes which contributed to impairment of wound healing process [36]. In our study, we investigate the role of nsulin local treatment for wound management, resulting from diabetes. Insulin significantly accelerate the wound healing by decrease the wound gap size and increase the contraction of the skin borders in comparison to the diabetic groups. Septic scar formation covered the unclosed edges in the control diabetic untreated group in comparison to insulin treated group. The formed scar completely fall in insulin treated group indicating end of skin restoration which appeared as pinkish color contractile wound, while in the control diabetic nontreated group, the scar in not fully fall down leaving slightly open wound and more wide wound edges. Insulin could promote wound healing response through inflammatory response modulation including proper inflammatory cell infiltration, resolution and enhancement of cell function [37]. Proper healing management requires macrophage influx for phagocytosis and digestion of tissue debris followed by neutrophilic infiltration in the wound, in addition to promotion of cell proliferation and migration via antiinflammatory cytokines and growth factors secretion which help in tissue repair [38]. Abundant inflammatory reaction with necrotic tissues and hemorrhages was noticed in the control diabetic nontreated group compared to Insulin wounds where less inflammatory reaction observed, suggested that insulin could induce diabetic wound healing through regulation of wound inflammatory response.

The best healing activity of insulin would be attributed to their physicochemical properties and antioxidant activities. Diabetes mellitus affects the kidney as the kidney grows large and the glomerular filtration rate (GFR) disrupted [39]. In association, most recent basic and clinical studies refer toward sclerosis and kidney failure.in our study the kidney function markers increased due to diabetes mellitus which decreased after insulin spry application. Moreover, increased activities of liver enzymes such as aspartate aminotransferase (AST), alanine aminotransferase (ALT), and Gama glutamyl tran peptidase (GGT) are markers of hepatocellular injury. The incensement of these markers is associated mainly with diabetes mellitus [40]. metabolic syndrome, and type 2 diabetes[41]. This study come in agreement with our study which decreased when insulin spray was applied localized on the wound. Furthermore, diabetes mellitus caused increased in the production of oxidative stress markers and the harmful effect resulted from reactive 
oxygen species (ROS). ROS produced due to the formation of advanced glycation end products from the reaction of glucose with plasma proteins, also these ROS initiate a chain reaction leading to reduced nitric oxide availability, increased markers of inflammation and chemical modification of lipoproteins, all of which may increase the risk of atherogenesis. The tissues damage was caused by hyperglycemia decreased by application of the insulin spry on the wound through removal and in activation of the ROS [42]. From the pathological point of view, the tissue samples treated with Insulin spray had good healing quality with better tissue matrix rearrangements and minimal inflammatory densities than the control diabetic untreated groups.

\section{REFERENCES}

1. Bancroft, J.D., Stevens, A., \& Dawswon, M.P. (1996). Theory and practice of histological techniques. 4th ed. Churchill Livingstone, Edinbergh, London and New York, 273:292.

2. Blakytny, R., \& Jude, E. (2006). The molecular biology of chronic wounds and delayed healing in diabetes. Diabetic Medicine, 23(6), 594-608.

3. Borenstein, M., Cohen, J., Rothstein, H. R., Pollack, S., \& Kane, J. M. (1992). A visual approach to statistical power analysis on the microcomputer. Behavior Research Methods, Instruments, \& Computers, 24(4), 565-572.

4. Bowers, L.D., \&, Wong E.T. (1980). Kinetic serum creatinine assays. II. A critical evaluation and review. Clin Chem. Apr;26(5):555-61.

5. Bowler, P.G. (2002). Wound pathophysiology, infection and therapeutic options. Ann Med, 34(6):419-27.

6. Brownlee, M. (2001). Biochemistry and molecular cell biology of diabetic complications. Nature, 414(6865), 813-820.

7. Buemi, M., Galeano, M., Sturiale, A., Ientile, R., Crisafulli, C., Parisi, A., ... \& Squadrito, F. (2004). Recombinant human erythropoietin stimulates angiogenesis and healing of ischemic skin wounds. Shock, 22(2), 169-173.

8. Chen, X., Liu, Y., \& Zhang, X. (2012). Topical insulin application improves healing by regulating the wound inflammatory response. Wound Repair Regen, 20(3):425-34.

9. Dacie, J.V., \& Lewis, S.M. (1991). Practical Hematology. $7^{\text {th }}$ Edition, Churchil Livingstone, Edinburgh, 54-79

10. Demidova-Rice, T.N., Hamblin, M.R., \& Herman, I.M. (2012). Acute and impaired wound healing: pathophysiology and current methods for drug delivery, Part 1: Normal and chronic wounds: biology, causes, and approaches to care. Adv skin wound care; 25(7): 304-314.

11. Doumas, B.T., Watson, W.A., \& Biggs, H.G. (1971). Albumin standards and the measurement of serum albumin with bromcresol green. Clin Chim Acta, 31(1):87-96.
12. Fawcett, J.K., \& Scott, J.E. (1960). A rapid and precise method for the determination of urea. J Clin Pathol, 13(2):156-9.

13. Gornall, A.G., Bardawill, C.J., \& David, M. M. (1949). Determination of serum proteins by means of the biuret reaction. J. Biol. Chem, 177:751-66, 1949

14. Guo, S., \& DiPietro, L.A. (2010). Factors Affecting Wound Healing. J Dent Res, Mar; 89(3): 219-229.

15. Howard, W., Robinson, J., Waide, Price., \& Corinne, G. Hogden, S. (1937). The estimation of albumin and globulin in blood serum: I. Astudy of the errors involved in the filtration procedure. J. Biol. Chem. 120:481-498.

16. Joseph, B. (1930). Insulin in the treatment of nondiabetic bed sores. Annals of surgery, 92(2), 318.

17. Koracevic, D., Koracevic, G., Djordjevic, V., Andrejevic, S., \& Cosic, V. (2001). Method for the measurement of antioxidant activity in human fluids. 356 J Clin Pathol, 54:356-361.

18. Lenzen, S. (2008). The mechanisms of alloxan and streptozotocin diabetes. Diabetologia, 51, 216-226,

19. Li, C., Yu, T., Liu, Y., Chen, X., \& Zhang, X. (2015). Topical application of insulin accelerates vessel maturation of wounds by regulating angiopoietin-1 in diabetic mice. The international journal of lower extremity wounds, 14(4), 353-364.

20. Mansbridge, J.N., Liu, K., Pinney, R.E., Patch, R., Ratcliffe, A., \& Naughton, G.K. (1999). Growth factors secreted by fibroblasts: role in healing diabetic foot ulcers. Diabetes Obes Metab, 1(5):265-79.

21. Marchesini G, Brizi M, Bianchi G, Tomassetti S, Bugianesi E, Lenzi M, McCullough AJ, Natale S, Forlani G, Melchionda N: Nonalcoholic fatty liver disease: a feature of the metabolic syndrome. Diabetes 50: 1844-1850, 2001

22. Martin, P., \& Leibovich, S.J. (2005). Inflammatory cells during wound repair: the good, the bad and the ugly. Trends Cell Biol; 15: 599-607.

23. Mathieu. D., Linke, J.C., \& Wattel, F. (2006). Nonhealing wounds. In: Mathieu DE, editor. Handbook on Hyperbaric Medicine. Amsterdam, The Netherlands: Springer.

24. Mogensen, C.E. (1971). Glomerular filtration rate and renal plasma flow in shortterm and long-term juvenile diabetes mellitus. Scand J Clin Lab Invest, 28: 91-100.

25. Misra, M., \& Aiman, U. (2012). Alloxan: An unpredictable drug for diabetes induction?. Indian journal of pharmacology, 44(4), 538.

26. Montgomery, H.A.C., \& Dymock, J. F. (1961). Colorimetric determination of nitrite. Analyst (86): 414.

27. Nishikimi, M., Rao, N. A., \& Yagi, K. (1972). The occurrence of superoxide anion in the reaction of reduced phenazine methosulfate and molecular oxygen. Biochemical and biophysical research communications, 46(2), 849-854. 
28. Ohkawa, H., Ohishi, N., \& Yagi, K. (1979). Assay for lipid peroxides in animal tissues by thiobarbituric acid reaction. Analytical biochemistry, 95(2), 351-358.

29. Robson, M. C., Steed, D. L., \& Franz, M. G. (2001). Wound healing: biologic features and approaches to maximize healing trajectories. Current problems in surgery, 2(38), 72-140.

30. Sadagurski, M., Yakar, S., Weingarten, G., Holzenberger, M., Rhodes, C. J., Breitkreutz, D., ... \& Wertheimer, E. (2006). Insulin-like growth factor 1 receptor signaling regulates skin development and inhibits skin keratinocyte differentiation. Molecular and cellular biology, 26(7), 2675-2687.

31. Saltiel, A.R., \& Pessin, J.E. (2002). Insulin signaling pathways in time and space. Trends Cell Biol, 12: 6571.

32. Saber, S., Khalil, R. M., Abdo, W. S., Nassif, D., \& El-Ahwany, E. (2019). Olmesartan ameliorates chemically-induced ulcerative colitis in rats via modulating $\mathrm{NF \kappa B}$ and Nrf-2/HO-1 signaling crosstalk. Toxicology and applied pharmacology, 364, 120-132.

33. Sheetz, M. J., \& King, G. L. (2002). Molecular understanding of hyperglycemia's adverse effects for diabetic complications. Jama, 288(20), 25792588.

34. Singh, N., Armstrong, D. G., \& Lipsky, B. A. (2005). Preventing foot ulcers in patients with diabetes. Jama, 293(2), 217-228.

35. Snyder, R. J. (2005). Treatment of nonhealing ulcers with allografts. Clinics in dermatology, 23(4), 388-395.

36. Reitman, S., \& Frankel, S. (1957). A colorimetric method for the determination of serum glutamic oxalacetic and glutamic pyruvic transaminases. American journal of clinical pathology, 28(1), 56-63.

37. Stojadinovic, O., Brem, H., Vouthounis, C.(2005). Molecular Pathogenesis of Chronic Wounds: The Role of $\beta$ - Catenin and c-myc in the Inhibition of Epithelization and Wound Healing. Am J Pathol; 167(1): 59-69.

38. Takahashi, Y., Akanuma, Y., Yazaki, Y., \& Kadowaki, T. (1999). Formation of distinct signaling complexes involving phosphatidylinositol 3-kinase activity with stimulation of epidermal growth factor or insulin-like growth factor-I in human skin fibroblasts. J Cell Physiol, 178(1):6975.

39. Tianyi, Yu., Min,G., Peilang, Y., Qing, P., Dan, L., Di, W., Xiong, Z., \& Yan, L. (2017). Topical insulin accelerates cutaneous wound healing in insulin-resistant diabetic rats. Am J Transl Res, 9(10): 4682-4693.

40. Wannamethee, S.G., Shaper, A.G, Lennon, L.,Whincup, P.H. (2005). Hepatic enzymes, the metabolic syndrome, and the risk of type 2 diabetes in older men. Diabetes Care, 28:2913-2918.

41. Wetzler, C., Kampfer, H., Stallmeyer, B., Pfeilschifter, J., \& Frank, S.(2000). Large and sustained induction of chemokines during impaired wound healing in the genetically diabetic mouse: prolonged persistence of neutrophils and macrophages during the late phase of repair. J InvestDermatol; 115: 245-253.

42. Wright, J.R., Scism-Bacon, J.L., \& Glass, L.C. (2006). Oxidative stress in type 2 diabetes: the role of fasting and postprandial glycaemia. Int $\mathrm{J}$ Clin Pract, 60(3): 308-314. 